\title{
Incorporating equivalent temperature in building cooling load prediction
}

\author{
Zixuan Wang ${ }^{a^{*}}$, Yuguo Li ${ }^{\mathrm{a}}$, Jiyun Song ${ }^{\mathrm{a}}$, Kai Wang ${ }^{\mathrm{b}}$, Pak Wai Chan ${ }^{\mathrm{c}}$ \\ a. Department of Mechanical Engineering, The University of Hong Kong, Hong Kong, P. R. China \\ b. Department of Civil Environmental and Geomatic Engineering, University College London, London, UK \\ c. Hong Kong Observatory, Hong Kong, P. R. China
}

\begin{abstract}
Buildings is accounted for a large fraction of urban energy use. Predicting building load is therefore significant for urban energy savings. The effects of sensible temperature on building energy demand have been widely studied, whereas the effects of humidity (latent temperature) is relatively less studied. The concept of equivalent temperature was adopted in this study to assess the effects of climate. A generic office building model was used to run simulations at mesoscale/local-scale. On average, latent cooling load accounted for $27.85 \%$ and $31.05 \%$ of the total cooling load in tropical and temperate cities, suggesting humidity plays a significant role in predicting building cooling demand in hot and humid areas. Moreover, equivalent temperature shows a robust correlation with the total building cooling load.
\end{abstract}

Peer-review under the responsibility of the organizing committee of the ICMB21.

Keywords: Equivalent temperature; Urban climate; Humidity; Building energy; Cooling load.

\section{Introduction/Background}

In addition to building characteristics and human behaviour, building energy consumption is strongly influenced by the local weather conditions. The effects of humidity have been less examined comparing with sensible temperature. In humid regions, a large amount of additional energy is consumed to maintain indoor humidity at a stable and comfortable level. The latent cooling load of buildings in Hong Kong accounts for a considerable fraction of the total load, evidencing the strong influence of moisture on building cooling energy demand, especially in places requiring high levels of dehumidification. A more comprehensive indicator, equivalent temperature, is thus needed to reflect the combined effects of temperature and moisture on building energy consumption. In this paper, we demonstrate the robust correlation between equivalent temperature and building cooling demand, and highlight the effects of humidity in regions with a hot and humid climate.

\section{Method}

\subsection{Equivalent temperature}

Equivalent temperature $\left(T_{e}\right)$ is defined in units of degree Celsius $\left({ }^{\circ} \mathrm{C}\right)$ as $T_{e}=\frac{H}{C_{p}}=T+\frac{L \omega}{C_{p}}$ [1], where $H$ is the moist static energy and $H=$ $C_{p} T+L \omega, C_{p}$ is the specific heat of air at constant pressure, $T$ is the air temperature, $L$ is the latent heat of vaporisation, and $\omega$ is the specific humidity. Hereafter, we refer to air temperature $T$ as the sensible temperature, and $\frac{L \omega}{C_{p}}$ (i.e. the difference between equivalent temperature and sensible temperature) as the latent temperature. Sensible temperature, latent temperature and equivalent temperature are collectively referred to as 'temperature'.

\subsection{Simulation setting and site selection}

Building energy simulation was performed using DeST, a dynamic building simulation tool developed by Tsinghua University. In this study, a typical 40-storey office building [2] was used as the model to simulate both local-scale and mesoscale climate. Each floor of the building is composed of the central core (with no AC supply), internal zone and four office zones (i.e., north, south, west and east) (Figure 1). The simulations are conducted for the period 2006 - 2015, using meteorological and solar radiation data from the NOAA and PVGIS.

we identified cities at similar altitudes and latitudes to those of Hong Kong $\left(\sim 32 \mathrm{~m}\right.$ and $\sim 22.3^{\circ} \mathrm{N}$, respectively). Similar altitudes and latitudes guarantee the comparable solar irradiances and sensible temperatures, and thus we can put focus on the impact of local humidity. Besides, the cities within similar latitudes are more likely to share similar building settings and also physics of energy transfer and consumption. According to the Köppen climate classification, regions between latitudes $21^{\circ} \mathrm{N}$ and $26^{\circ} \mathrm{N}$ are classified into one of three main climate categories: tropical, dry, and temperate. We excluded city stations if $10 \%$ or more of their datasets were 'unrecorded'. Thus, nine city stations, three from each of the aforementioned climate categories, were included in the study. For local-scale simulations, weather data were obtained from six local weather stations of the Hong Kong Observatory according to their urbanization degree. 


\section{ICMB21}

\section{Result}

\subsection{Results of building energy simulations in the mesoscale and local scale}

Dry regions always experience higher sensible cooling demand than do temperate and tropical regions. Overall, the sensible cooling demand is the highest in the dry climate, followed by the tropical climate. The six cities in the tropical and temperate regions are characterised by a humid climate, especially during summer. The latent cooling load in humid areas accounts for a substantial fraction (as high as $31.05 \%$ in temperate regions) of the total cooling load. These data highlight the important effect of humidity on building energy consumption in humid regions.

For the cooling load in six local stations in Hong Kong, the latent cooling load at HKO is exceptionally high due to the significant urban moisture island (UMI) effect (i.e. moisture magnitude is higher in urban area than in rural area). The combined effect of the weakened wind environment and elevated anthropogenic moisture release leads to increasing humidity levels in the city. Generally, HKO has the largest average total cooling load, but the difference between the stations is not significant.

\subsection{Correlation of temperature with cooling loads}

We explore the relationship between equivalent temperature and total cooling load. After separating the data for dry (desert) and non-dry (tropical and temperate) cities, there is a high correlation between equivalent temperature and total cooling demand (adjusted $\mathrm{R}^{2}=0.89$ for dry area, adjusted $\mathrm{R}^{2}=0.90$ for non-dry area) (Figure 2). The sharp distinction between the observations in the dry and non-dry cities could be due to the varying correlation between sensible (latent) temperature and sensible (latent) cooling demand.

Next, we analyse the simulated cooling load in the six stations of interest in Hong Kong. The results show that equivalent temperature has a stronger correlation with total cooling load than does sensible temperature (adjusted $\mathrm{R}^{2}$ coefficients $=0.95$ and 0.54 , respectively) (Figure 3,4 ). Equivalent temperature is a strong indicator of cooling demand especially under local effects (e.g. urbanisation). In a given region, the higher the equivalent temperature is, the larger the total cooling demand is expected to be.

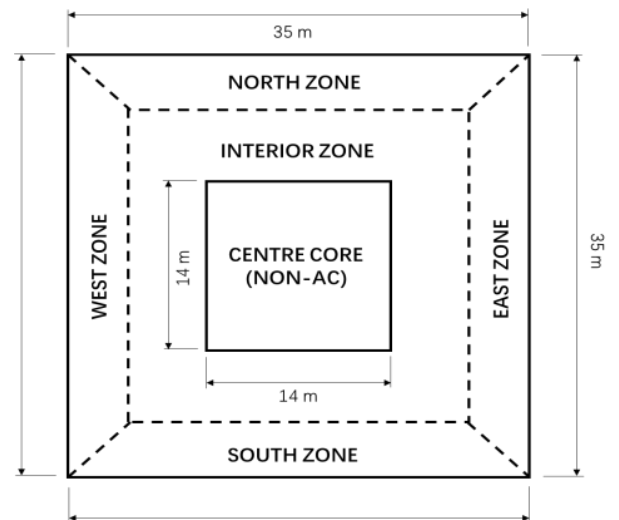

Figure 1. Typical floor layout of the generic office building

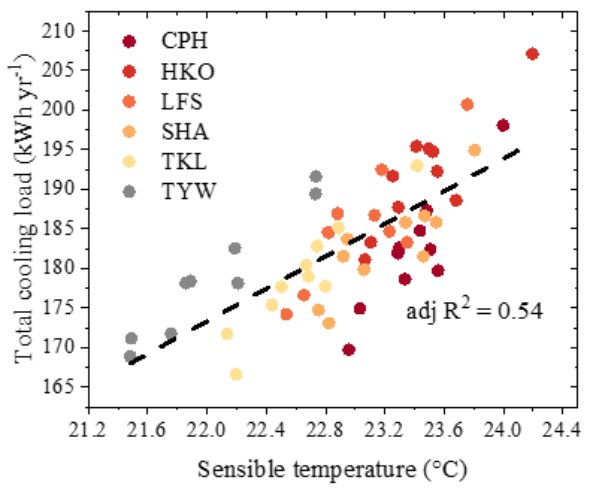

Figure 3. Correlation between sensible temperature and total cooling load

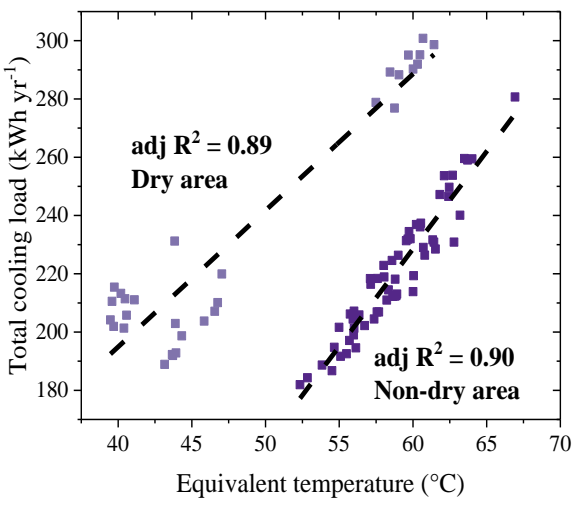

Figure 2. Correlation between equivalent temperature and total cooling load

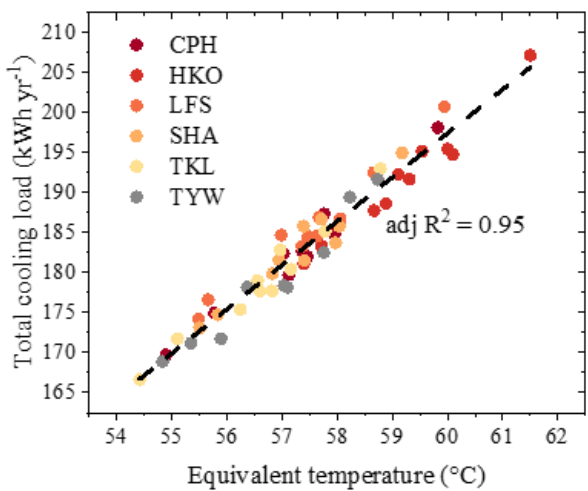

Figure 4. Correlation between equivalent temperature and total cooling load

\section{References}

[1] Pielke Sr., R. A., Davey, C., \& Morgan, J. (2004). Assessing "global warming” with surface heat content. Eos, Transactions American Geophysical Union, 85(21), 210-211.

[2] Lam, J. C., \& Hui, S. C. (1996). Sensitivity analysis of energy performance of office buildings. Building and Environment, 31(1), 27-39. 